\title{
Finite Element
}

\section{Simulation for Structural} Response of U7Mo Dispersion Fuel Plates Via Fluid-Thermal-

\section{Structural Interaction}

\author{
ASME 2010
}

\section{Hakan Ozaltun}

Herman Shen

Pavel Medvedev

The INL is a

U.S. Department of Energy

National Laboratory

operated by

Battelle Energy Alliance

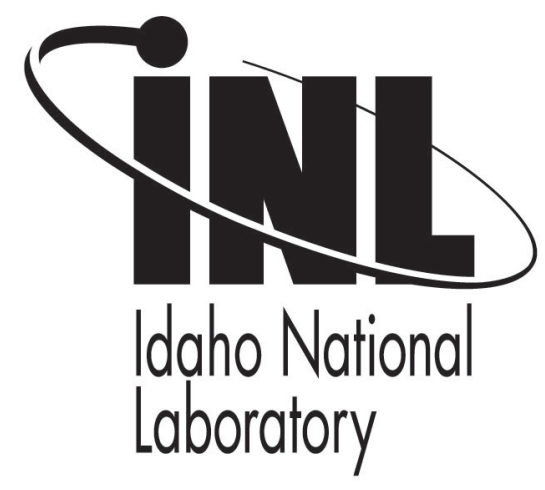

\section{November 2010}

This is a preprint of a paper intended for publication in a journal or proceedings. Since changes may be made before publication, this preprint should not be cited or reproduced without permission of the author. This document was prepared as an account of work sponsored by an agency of the United States Government. Neither the United States Government nor any agency thereof, or any of their employees, makes any warranty, expressed or implied, or assumes any legal liability or responsibility for any third party's use, or the results of such use, of any information, apparatus, product or process disclosed in this report, or represents that its use by such third party would not infringe privately owned rights. The views expressed in this paper are not necessarily those of the United States Government or the sponsoring agency. 


\section{FINITE ELEMENT SIMULATION FOR STRUCTURAL RESPONSE OF U7MO DISPERSION FUEL PLATES VIA FLUID-THERMAL-STRUCTURAL INTERACTION}

\author{
Hakan Ozaltun \& Herman Shen \\ Department of Mechanical Engineering \\ Ohio State University, 201 W. 19th Avenue \\ Columbus/OH - 43210, USA
}

\author{
Pavel Medvedev \\ Material and Fuel Complex \\ Idaho National Laboratory, P.O. Box 1625 \\ Idaho Falls/ID - 83415, USA
}

\begin{abstract}
This article presents numerical simulation of dispersion fuel mini plates via fluid-thermal-structural interaction performed by commercial finite element solver COMSOL Multiphysics to identify initial mechanical response under actual operating conditions. Since fuel particles are dispersed in Aluminum matrix, and temperatures during the fabrication process reach to the melting temperature of the Aluminum matrix, stress/strain characteristics of the domain cannot be reproduced by using simplified models and assumptions. Therefore, fabrication induced stresses were considered and simulated via image based modeling techniques with the consideration of the high temperature material data. In order to identify the residuals over the U7Mo particles and the Aluminum matrix, a representative SEM image was employed to construct a microstructure based thermo-elasto-plastic FE model. Once residuals and plastic strains were identified in micro-scale, solution was used as initial condition for subsequent multiphysics simulations at the continuum level. Furthermore, since solid, thermal and fluid properties are temperature dependent and temperature field is a function of the velocity field of the coolant, coupled multiphysics simulations were considered. First, velocity and pressure fields of the coolant were computed via fluidstructural interaction. Computed solution for velocity fields were used to identify the temperature distribution on the coolant and on the fuel plate via fluid-thermal interaction. Finally, temperature fields and residual stresses were used to obtain the stress field of the plates via fluid-thermal-structural interaction.
\end{abstract}

Keywords: dispersion fuel plates, multiscale, multiphysics, microstructure based fem

\footnotetext{
Corresponding author. Tel: $+1.614 .2922280 \mid$ Fax: +1.614 .2928290$

E-mail address: shen.1@osu.edu (Prof. Herman Shen)
}

\section{INTRODUCTION}

Initiated in late 1970, the primary objective of the Reduced Enrichment for Research and Test Reactors (RERTR) program is to develop the technology to minimize the use of Highly Enriched Uranium (HEU) for most civilian applications. RERTR fuel development program aims to develop fuel types that would substitute high enriched uranium with proliferation resistant, low enriched uranium $\left(<20 \%{ }^{235} \mathrm{U}\right)$ for research reactors [1]. However, once the amount of the enriched Uranium per unit volume is reduced, there will be a sudden drop in the fission rate. Consequently, higher densities should be employed to compensate for lower fission rate caused by the reduction of enriched Uranium per unit volume. Many research reactors can be satisfactorily operated with Silicon based $\left(\mathrm{U}_{3} \mathrm{Si}_{2}-\mathrm{Al}\right.$ ) dispersive fuels lower (up to $5 \mathrm{~g} / \mathrm{cm}^{3}$ ) densities. However, several high performance reactors such as ATR (Advanced Test reactor), HFIR (High Flux Isotope Reactor), MITR Massachusetts Institute of Technology Reactor, NBSR (National Bureau of Standards Reactor) and MURR (Missouri University Research Reactor) require even higher densities (up to $10 \mathrm{~g} \mathrm{U} / \mathrm{cm}^{3}$ ). Challenge associated with this, the fuel with high-uranium density should remain stable during irradiation as well as during the fabrication process. Among several proposed alloys, U-Mo based fuels are found to be the most promising candidate for fuels with higher densities. Molybdenum extends the stability of the gamma phase of the domain, since this phase is known to be stable under the desired irradiation conditions. U-Mo has a low neutron caption cross-section, good irradiation behavior and acceptable swelling response [2-4].

Dispersive fuel elements have been preferred in the research and test nuclear reactors due to their reliability, robust thermal and mechanical response [5]. For development of Molybdenum based dispersion fuels with higher densities, U-Mo particles are dispersed in the Aluminum matrix. An aggressive research has been carried out in Material and Fuel Complex (MFC) of Idaho 
National Laboratory (INL) to benchmark U-Mo based dispersion and monolithic fuel types. One of the major challenges of developing a new fuel type is to predict the structural response under thermo-mechanical loading. Number of irradiation experiments has been carried out to experimentally observe the structural response of the plates [69]. However, structural simulation of U-Mo alloy based dispersive fuel elements is in their early development stages.

Since fabrication of dispersive plates requires thermally driven procedures, this process should be understood well to accurately simulate the structural response under actual operating conditions. The process of producing of U-Mo based dispersion plates by Hot Rolling is as follows. Fabrication is according the well established picture-frame technique. This method has been used successfully for years for commercial fabrication of Aluminum-based dispersion fuel plates. The frame contains a compact that is assembled in a cavity machined into the frame plate. Fuel compact is prepared with atomization process as explained in elsewhere [10]. U-7Mo powder is mixed with 6061AL powder. The blended powder is then compacted under pressure and placed in a frame made of $6061 \mathrm{Al}$ alloy. Cover plates are placed to the top and the bottom to form the cladding as illustrated schematically in Fig. 1.

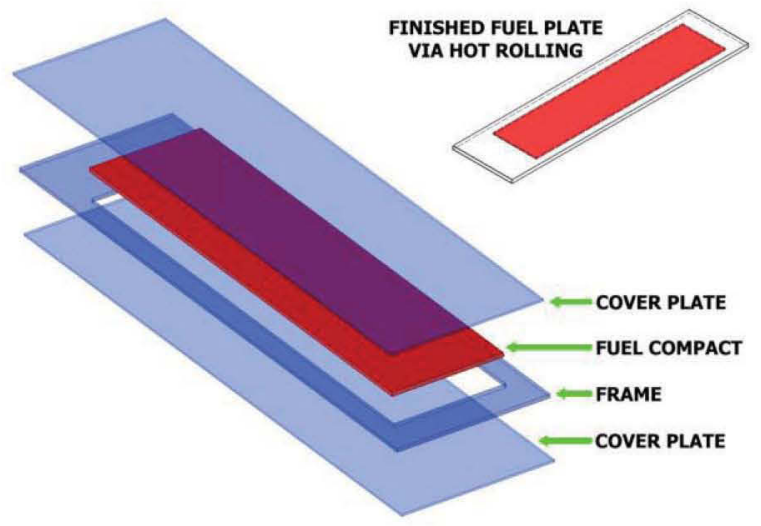

Figure 1 Picture frame technique

Assembly is then welded together and rolled under pressure to form a plate to reach the targeted thickness. The miniplates are produced by hot and cold rolling. The plates are hot rolled where the plates are in the furnace approximately $100 \mathrm{~min}$ at $500{ }^{\circ} \mathrm{C}$ and $15 \mathrm{~min}$ outside the furnace during the actual rolling. The plates are then cold rolled further to achieve the targeted thickness [11]. Dimensions for finished product are shown in Fig. 2.

The final high-temperature process of the fuel plates are exposing them a blister annealing for testing purposes. This is a standard practice to ensure that no blisters develop on the surface, which would be an indication of poor bonding between the fuel meat and the cladding. During blister annealing, plates are exposed to $485^{\circ} \mathrm{C}$ for 60 minutes.

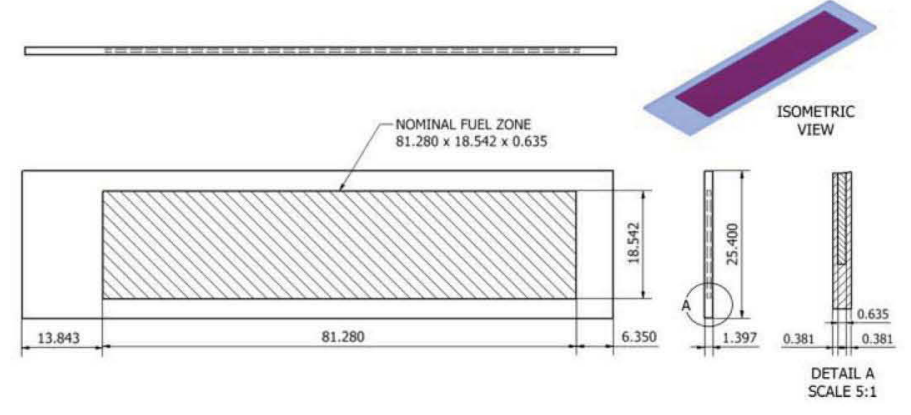

Figure 2 Dimensions [mm] of dispersion fuel plate

Once mini plates are fabricated as described, total $32 \mathrm{mini}$ plates are then assembled into 4 capsules made of Al6061-T6. The capsules are positioned vertically in a basket and are cooled by direct contact with primary coolant. Flow velocities over the plates are $11 \mathrm{~m} / \mathrm{sec}$ and $14[\mathrm{~m} / \mathrm{sec}]$ for outer and inner channels respectively. Approximate pressure of the primary coolant in ATR is $2.56 \mathrm{MPa}$. Representative schematic of plate assembly is shown in Fig. 3.

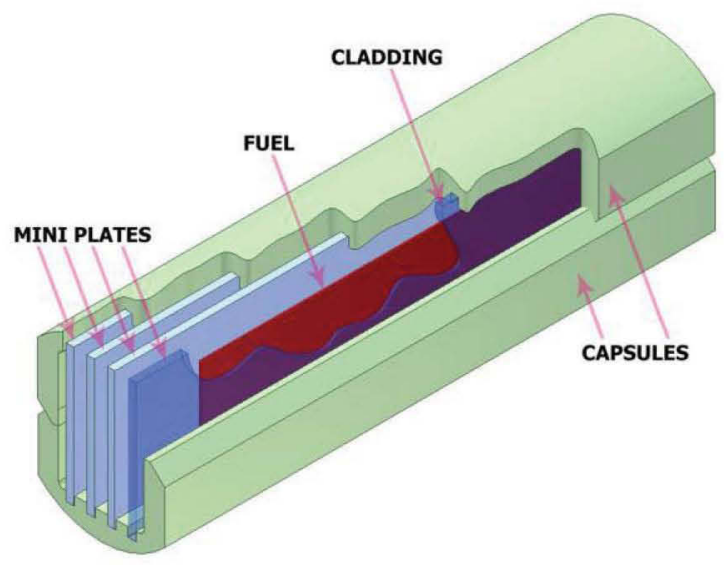

Figure 3 Schematic of a plate assembly

\section{MODELLING}

There are numbers of published works investigating thermal stresses in multi-layered structures via thermo-structural coupling. However, available publications on multiscalemultiphysics simulations of multi-layered structures with consideration of residual stresses are still scarce. In addition, simulation efforts for structural response of newly developed U-Mo alloy based mini fuel plates are in very early stages. This article discusses the simulation efforts for U-Mo based fuel plates to provide in-depth understanding of Aluminum matrixfuel particles stress/strain characteristics via microstructural based FE simulation techniques. The thermo-mechanical behavior of the plates and their initial response under actual 
operating conditions with consideration of the residuals via fluid-thermal-structural interaction will be provided. The framework for the methodology and the techniques that were used for the multiscale-multiphysics simulations will be explained.

To provide an effective tool for assessment of structural response of the plates, it would be more realistic to use a simulation model as close as possible to the actual product. As explained previously, high temperatures are required during the fabrication process to achieve a proper thermo-mechanical bonding. Since multi layered structure has different components with different thermal and mechanical properties, residual stresses and stress gradients over the mechanical domain should be expected once the thermal transient is completed. It is important to emphasize that residual stresses are known to influence materials mechanical properties such as creep or fatigue life. Sometimes, the effect on mechanical properties is beneficial; and many other times, the effect is very deleterious. Improperly identified residuals would lead very deleterious results and consequently very poor conclusions. Therefore, identifying these stresses and including the residuals into subsequent simulations are crucial for accurate numerical results. However, considering fuel particles are dispersed in an Aluminum matrix, residuals cannot be simulated by simplified assumptions. Since location, size and orientation of the particles would greatly alter the mechanical response of the domain; involvement of microstructural characteristics should be considered. For this purpose, a non-linear thermomechanical simulation in micro-scale should be employed first.

It is well recognized that microstructure controls the physical and mechanical properties of a material. Since microstructures are such complex ensembles, correlating known microstructures with their physical and mechanical properties becomes very complicated task. Even single-phased materials may have such microstructural distribution and orientations that affect physical and mechanical properties and consequently structural response. Accurate representation of a microstructure is quite important across a wide range of disciplines for the prediction of properties and the simulation of structural response under mechanical and thermal loading. Analytical models and assumptions might provide acceptable predictions for relatively simple configurations. However, these approximations become very questionable in harsh environments for critical mechanical components such as reactor structures or nuclear fuels. Materials often contain defects and second phases in small fractions that can ultimately affect integrity and reliability. Because the two neighboring phases may have different thermal and mechanical properties, and these properties are dependent to orientation of the phases, other problems become quite significant such as residual stresses. Since, microstructural orientation and behavior is very difficult to predict, it is a challenging problem for scientists to quantify mechanical response at continuum level.
One way of computing the macroscopic behavior of a material sample with a complex microstructure is to construct a simulation model based on a micrograph of representative sectioning of the material. For this purpose, an effective numerical procedure, Image Based Finite Element has been developed by the scientists to implement mechanical and thermal properties and even determine structural response. This technique is very efficient and accurate for the numerical simulation of porous, composite and multi-phased materials with very complex geometries. The quality of the results produced with such a model obviously depends on the number of sections obtained from the material. To achieve desired accuracy, a microstructural characterization should be carried out. Then, representative microstructure can be used to produce realistic image-based finite element models [12-16]

There are several tools are available for image processing such as OOF2 with Abaqus interaction developed by NIST, $\mu$ FEM with Ansys interaction developed by ORNL, LaGriT developed by LANL or iso2mesh with Matlab interaction. Benchmarking these tools is out of focus of this article. However, any of these tools can be successfully used for converting a microstructural image to a Finite element mesh. Since Comsol Multiphysics was employed for the multiphysics simulations presented in this article and Comsol has very effective Matlab interaction, image processing toolbox of Matlab and iso2mesh were found to be more effective.

Once residuals and plastic strains due to fabrication process are identified via microstructural based analysis, solution should be used as initial condition for subsequent multi-physics simulations in continuum level. In addition, since thermal response of the structure is mainly driven by amount of heat removed by primary coolant and heat removal rate is a function of the coolant velocity field and coolant temperature increases non-linearly while coolant travels along the path in the mini plate capsule and the heat generation rate has a non-uniform distribution along the plate width, fluid-structure interaction should be carefully coupled with fluid-thermal interaction before coupling them with structural mechanics. To achieve this, velocity and pressure fields of the coolant should be computed via fluid-structural interaction with thermal dependency. Computed velocity and pressure fields then should be used to identify temperature fields on both coolant and on the fuel plate via coupled fluid-thermal and thermal-structural interaction. Finally, computed temperature fields and residual stress distribution should be supplied to the solver to obtain the accurate mechanical response of a plate via coupled FluidThermal-Structural interaction.

\section{MATHEMATICAL PRELIMINARIES \\ 3.1. Structural Mechanics}

Mechanical properties were assumed to be independent of direction but dependent of temperature. Hence, modulus of elasticity (E), Poisson's ratio (v) and shear modulus $(G)$ were defined as follows, 
$E_{x}=E_{y}=E_{z}=E(T)$

$v_{x y}=v_{y x}=v_{x z}=v_{z x}=v_{y z}=v_{z y}=v(T)$

$G(T)=G_{x y}=G_{x z}=G_{y z}=\frac{E(T)}{2 \cdot[1+v(T)]}$

Assuming the material of interest undergoes small strains, linearized form of the strain tensor can be expressed as,

$\varepsilon_{i j}^{\text {total }}=\frac{1}{2}\left(\frac{\partial u_{i}}{\partial u_{j}}+\frac{\partial u_{j}}{\partial u_{i}}\right)$

Where, $\quad \varepsilon_{i j}$ and $u$ strain tensor and displacements respectively. At each point of the plate, the total-strain components $\varepsilon_{i j}^{\text {total }}$ are represented as the sum of the corresponding components of the elastic, plastic, thermal and initial ones. Such as,

$\varepsilon_{i j}^{\text {total }}=\frac{1}{2}\left(u_{i, j}+u_{j, i}\right)=\varepsilon_{i j}^{e l}+\varepsilon_{i j}^{p l}+\varepsilon_{i j}^{\text {th }}+\varepsilon_{i j}^{i n}$

Furthermore, thermal strain tensor $\varepsilon_{k l}^{t h}$ is expressed by,

$\varepsilon_{k l}^{t h}=\alpha_{k l}(T) \times \Delta T$

$\alpha_{k l}(T)$ is the tensor governing coefficient of thermal expansion, and $\Delta T$ is the temperature change from the reference point. The mechanical constitution of the plate was assumed to be in the following form:

$$
\sigma_{i j}=D_{i j k l} \times \varepsilon_{k l}^{e l}+\sigma_{i j}^{i n}
$$

Where, $D_{i j k l}$ is $6 \times 6$ temperature dependent elasticity matrix (i.e. $D_{i j k l}(T)$ ), $\varepsilon_{k l}^{e l}$ elastic strain tensor, and $\sigma_{i j}^{i n}$ is initial or namely residual stresses. Substituting elastic strains into the mechanical constitution gives the stress distribution on the plate expressed as,

$\sigma_{i j}=D_{i j k l} \times\left(\varepsilon_{k l}^{\text {total }}-\varepsilon_{k l}^{p l}-\varepsilon_{k l}^{t h}-\varepsilon_{k l}^{i n}\right)+\sigma_{i j}^{i n}$

Material flow was defined according to Von-Mises rule as follows,

$F_{d}\left(\sigma_{i j}, \bar{\varepsilon}\right)=\frac{1}{2} \sigma_{i j}^{\prime} \sigma_{i j}^{\prime}-\frac{1}{3} \sigma_{s}^{2}(\bar{\varepsilon})$

\subsection{Fluid Flow}

Generalized version of the Navier-Stokes equations was solved over the domain to allow for variable viscosity. Starting with the momentum balance in terms of stresses, the generalized equations in terms of transport properties and velocity gradients can be expressed in momentum transport equation defined as follows;

$\rho \frac{\partial u}{\partial t}-\nabla \cdot\left[\eta\left(\nabla u+(\nabla u)^{T}\right)\right]+\rho(u \cdot \nabla) u+\nabla p=F$

Equation of continuity for incompressible fluids is;

$\nabla \cdot u=0$

Where $\eta$ is the dynamic viscosity, $\rho$ is the density, $u$ is the velocity field, $\mathrm{P}$ is the pressure and $\mathrm{F}$ is volume force field. Temperature dependent data for viscosity and density was used to allow the thermal effects.

\subsection{Thermal Transport}

The fundamental law governing heat transfer is the first law of thermodynamics, or the principle of conservation of energy. The basic law is usually expressed in terms of temperature for convenience. Following heat equation solved over the coolant domain;

$$
\rho C_{p} \frac{\partial T}{\partial t}+\nabla \cdot(-k \nabla T)=Q-\rho C_{p} \mathrm{u} \cdot \nabla T
$$

Where $\rho$ is the density, $C_{p}$ is the specific heat capacity at constant pressure, $T$ is absolute temperature, $k$ is the thermal conductivity, $u$ is the velocity vector, $Q$ is the heat sources other than viscous heating. For solid, $u$ (velocity vector) is set to be zero and therefore, governing equation for pure conductive heat transfer in fuel foil and cladding is expressed as;

$$
\rho C_{p} \frac{\partial T}{\partial t}+\nabla \cdot(-k \nabla T)=Q
$$

Heat transfer coefficient between the bulk of the fluid and the cladding surface was computed via Dittus-Boelter correlation;

$$
h=\frac{k_{w}}{D_{H}} N u
$$

Where $\mathrm{k}_{\mathrm{w}}$ thermal conductivity of the coolant, $D_{H}-D_{i}$ is hydraulic diameter and $N u$ is Nusselt number formulated as;

$$
N u=0.023 \cdot \operatorname{Re}^{0.8} \cdot \operatorname{Pr}^{n}
$$

Where Re - Reynolds number, $\mathrm{Pr}$ - Prandtl number and $\mathrm{n}=0.4$ 


\section{MATERIAL PROPERTIES}

As the hot rolling temperature reaches $500^{\circ} \mathrm{C}$, material properties at such high temperatures are crucial to obtain more accurate simulation results. These properties and experimental details are available elsewhere [17-22]. For completeness, compilation of the material properties that were used in the multiphysics simulations is given in Table 1 below.

Table 1 Material Property ${ }^{[17-22](*)}$

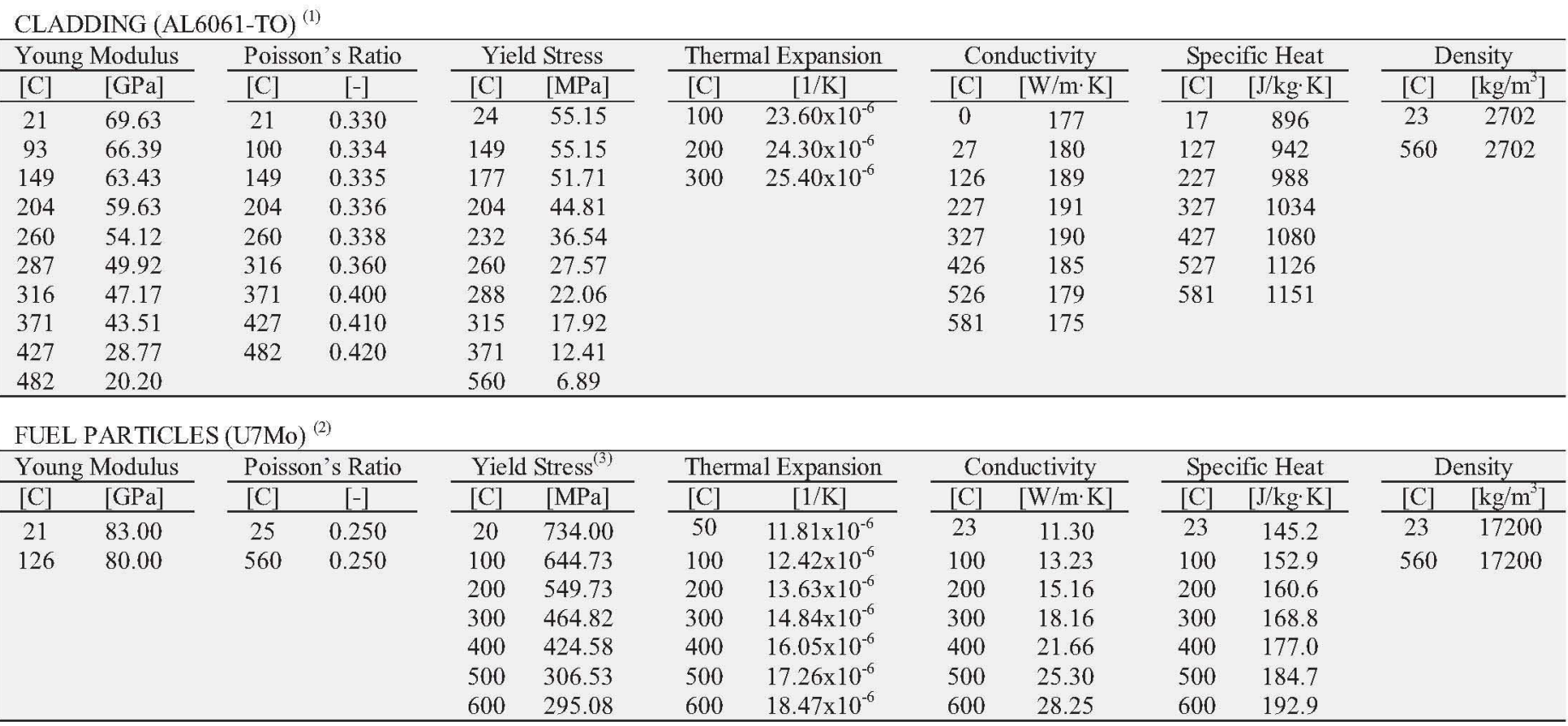

MATRIX $(40 \% \mathrm{U} 7 \mathrm{Mo}+60 \% \mathrm{AL} 6061)^{(4)}$

\begin{tabular}{|c|c|c|c|c|c|c|c|c|c|c|c|c|c|}
\hline \multicolumn{2}{|c|}{ Young Modulus } & \multicolumn{2}{|c|}{ Poisson's Ratio } & \multicolumn{2}{|c|}{ Yield Stress } & \multicolumn{2}{|c|}{ Thermal Expansion } & \multicolumn{2}{|c|}{ Conductivity } & \multicolumn{2}{|c|}{ Specific Heat } & \multicolumn{2}{|c|}{ Density } \\
\hline$[\mathrm{C}]$ & [GPa] & {$[\mathrm{C}]$} & {$[-]$} & [C] & {$[\mathrm{MPa}]$} & [C] & {$[1 / \mathrm{K}]$} & [C] & {$[\mathrm{W} / \mathrm{m} \cdot \mathrm{K}]$} & [C] & {$[\mathrm{J} / \mathrm{kg} \cdot \mathrm{K}]$} & {$[\mathrm{C}]$} & {$\left[\mathrm{kg} / \mathrm{m}^{3}\right]$} \\
\hline 21 & 74.98 & 25 & 0.300 & 24 & 326.69 & 50 & $18.4 \times 10^{-6}$ & 25 & 98 & 26 & 325 & 23 & 6711 \\
\hline 93 & 72.22 & 100 & 0.300 & 100 & 290.98 & 100 & $18.6 \times 10^{-6}$ & 100 & 103 & 102 & 343 & 560 & 6711 \\
\hline 149 & 70.06 & 149 & 0.300 & 149 & 272.36 & 200 & $19.3 \times 10^{-6}$ & 150 & 105 & 202 & 359 & & \\
\hline 204 & 67.78 & 204 & 0.300 & 200 & 247.39 & 300 & $19.9 \times 10^{-6}$ & 200 & 106 & 302 & 371 & & \\
\hline 260 & 64.47 & 260 & 0.300 & 300 & 198.06 & 400 & $20.6 \times 10^{-6}$ & 250 & 106 & 402 & 386 & & \\
\hline 287 & 61.95 & 316 & 0.320 & 371 & 181.95 & 500 & $20.0 \times 10^{-6}$ & 300 & 107 & 451 & 402 & & \\
\hline 371 & 58.11 & 371 & 0.340 & 400 & 176.77 & 600 & $20.4 \times 10^{-6}$ & 350 & 107 & 501 & 410 & & \\
\hline 427 & 49.26 & 427 & 0.350 & 500 & 127.80 & & & 400 & 107 & & & & \\
\hline 482 & 44.12 & 482 & 0.350 & 560 & 122.80 & & & 500 & 107 & & & & \\
\hline
\end{tabular}

COOLANT $^{(5)}$

\begin{tabular}{|c|c|c|c|c|c|c|c|c|c|c|c|}
\hline \multicolumn{2}{|c|}{ Density } & \multicolumn{2}{|c|}{ Conductivity } & \multicolumn{2}{|c|}{ Specific Heat } & \multicolumn{2}{|c|}{ Heat Transfer Coef } & \multicolumn{2}{|c|}{ Kin. Viscosity } & \multicolumn{2}{|c|}{ Dyn. Viscosity } \\
\hline [K] & {$\left[\mathrm{kg} / \mathrm{m}^{3}\right]$} & {$[\mathrm{K}]$} & {$[\mathrm{W} / \mathrm{mK}]$} & {$[\mathrm{K}]$} & {$[\mathrm{J} / \mathrm{kgK}]$} & {$[\mathrm{K}]$} & {$\left[\mathrm{W} /\left(\mathrm{m}^{2} \cdot \mathrm{K}\right)\right]$} & {$[\mathrm{K}]$} & {$\left[\mathrm{m}^{2} / \mathrm{s}\right]$} & {$[\mathrm{K}]$} & [Pa.s] \\
\hline 274 & 1003.95 & 273 & 0.5562 & 274 & 4216.58 & 274 & 41346 & 274 & $1.79 \times 10^{-6}$ & 273 & $1.79 \times 10^{-3}$ \\
\hline 300 & 997.65 & 300 & 0.6056 & 300 & 4181.48 & 300 & 57303 & 300 & $8.53 \times 10^{-7}$ & 300 & $8.52 \times 10^{-4}$ \\
\hline 350 & 975.71 & 350 & 0.665 & 350 & 4191.84 & 340 & 78314 & 350 & $3.82 \times 10^{-7}$ & 350 & $3.73 \times 10^{-4}$ \\
\hline 400 & 940.67 & 400 & 0.687 & 400 & 4262.9 & 400 & 102745 & 400 & $2.32 \times 10^{-7}$ & 400 & $2.17 \times 10^{-4}$ \\
\hline 450 & 892.8 & 450 & 0.6777 & 450 & 4398.89 & 440 & 111376 & 450 & $1.77 \times 10^{-7}$ & 450 & $1.55 \times 10^{-4}$ \\
\hline 500 & 832.39 & 500 & 0.6431 & 500 & 4658.38 & 500 & 116649 & 500 & $1.46 \times 10^{-7}$ & 500 & $1.23 \times 10^{-4}$ \\
\hline
\end{tabular}

(1) Reference [17] claims that Poisson Ratio is independent of temperature. Data from [22] was used instead for both Poisson's Ratio and Young Modulus.

(2) Unreported particle properties for U7Mo were approximated with properties of U10Mo monolithic plates.

(3) Hardness data was used to approximate the yield level for U10Mo and U7Mo.

(4) Except conductivity and specific heat reported by Lee in [20] and [21], the matrix properties were computed by rule of mixture.

(5) Heat transfer coefficient was computed by using Dittus-Boelter correlation.

(*) No extrapolation was performed for unknown data. Data for outside the bounds was approximated to the nearest neighbor.

Interpolations between the known temperatures were performed by piecewise cubic splines. 


\section{HOT ROLLING and RESIDUALS}

\subsection{Microstructure Based FE Model}

Since fuel particles are dispersed in an Aluminum matrix and location, size and orientation of the particles would alter the structural response of the domain; involvement of microstructural characteristics should be considered and consequently, numerical model should include these geometric characteristics. For this purpose, a non-linear thermomechanical simulation in micro-scale should be employed first. Then, solution of the micro-model can be used as initial condition for the subsequent simulations in the continuum level. Since every proceeding simulations is built on the residuals presented here, the accuracy of this simulation is quite important. At this point, the reader should be aware of the deterministic nature of this technique. It is quite important to note that the representative micro-structure and its location in the mechanical domain would alter the simulation results. However, since dispersion matrix has relatively simple configuration and the ultimate goal of this simulation is to obtain the structural response of the Aluminum matrix and the matrix material reaches to its yield level, results presented here are satisfactory for use in subsequent simulations. On the other hand, if the particle response alone is the concern, then, more detailed SEM investigations at various sections should be carried out to increase the accuracy via statistical approaches.

To calculate the fabrication induced residuals on the dispersion fuel compound (U7Mo+Al6061) after Hot Rolling process, general purpose commercial FE solver, Comsol Multiphysics was employed and computational clusters at Idaho National Laboratories was utilized. An image of representative microstructure was used to construct the model. SEM image of representative section is shown in Fig. 4a.

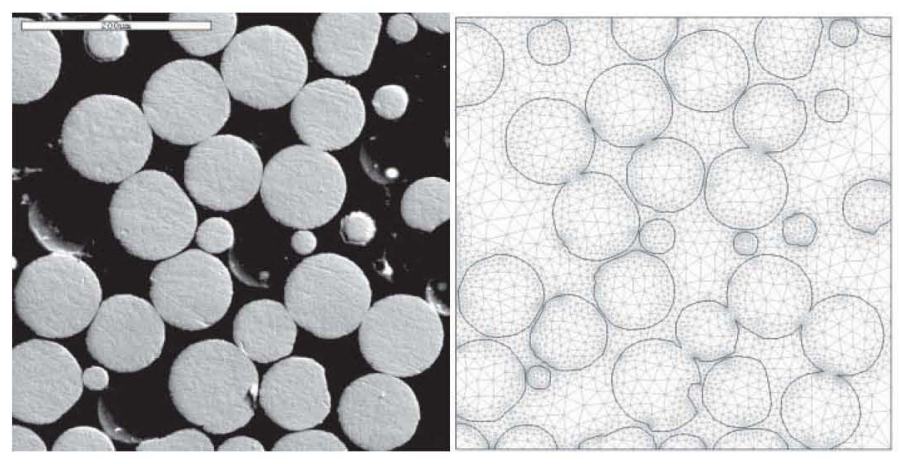

Figure 4 Microstructural image and resulting FE model

Image processing toolbox of Matlab and iso2mesh was employed to convert the microstructure to a Finite Element mesh. An appropriate number of seeds are assigned to the particle boundaries. First, the fuel particles were meshed; then, matching mesh was assigned to Aluminum matrix. At the particle boundaries, a denser mesh was used to increase the accuracy of the solution. Resulting finite element mesh is shown in Fig. 4b.
One node (lower left corner) of the model was fixed and horizontal boundary at the bottom was constrained to restrict the motion on the vertical direction. Fuel was represented by using quadratic triangular elements totaling 7408 elements, while cladding contains 4135 quadratic triangular elements. Elasto-thermo-perfectly-plastic material models were assigned to both 6061 Aluminum matrix and U7Mo fuel particles to simulate thermo-plasticity. Elasto-plastic parametric solver with reduced integration was used to minimize the computational expense. Since amount of time under temperature is small, thermal creep was assumed to have negligible effect. It was also assumed that complete mechanical bonding would be achieved at exact hot rolling temperature, and therefore $500^{\circ} \mathrm{C}$ was assumed to be reference point for the hot rolling simulation. From $500 \mathrm{C}, 20$ sub-steps were used to reach the room temperature. Solution was stored for every $25^{\circ} \mathrm{C}$ temperature drop for mechanical history.

\subsection{Results and Discussions}

Equivalent stress distribution over the domain is shown in Fig. 5. It was noted a complete plastic deformation of the matrix material (A16061TO) with tensile residuals and compressive stresses on the particles (U7Mo). In Fig. 5, particles register stresses less than their yield level. However, existence of several hot spots was noted. It was understood that even though there are higher local residuals on the particles, matrix material holds approximately $55 \mathrm{MPa}$ residuals at the end of hot rolling.

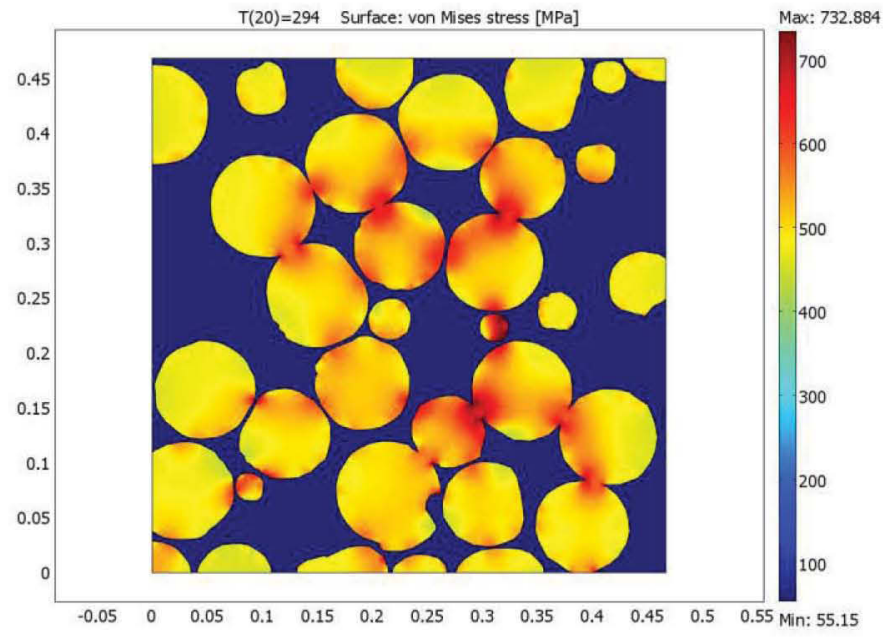

Figure 5 Equivalent stress distribution on the matrix

Once solution in micro level was obtained, a 2D symmetric model was constructed to solve the problem in macro level. Similarly, it was assumed $500^{\circ} \mathrm{C}$ is the perfect bonding temperature and 20 sub-steps were used to reach the room temperature. For every $25^{\circ} \mathrm{C}$ temperature drop solution was stored. Micro structure was assumed to be repetitive. Consequently, solution of micro model was supplied to the 2D continuum model as periodic condition. Similar meshing methodology and $\mathrm{FE}$ construction techniques were employed. 
Equivalent stress distribution over the plate and the particles is shown in Fig. 6. Solution was compared with Fig. 5 for verification.

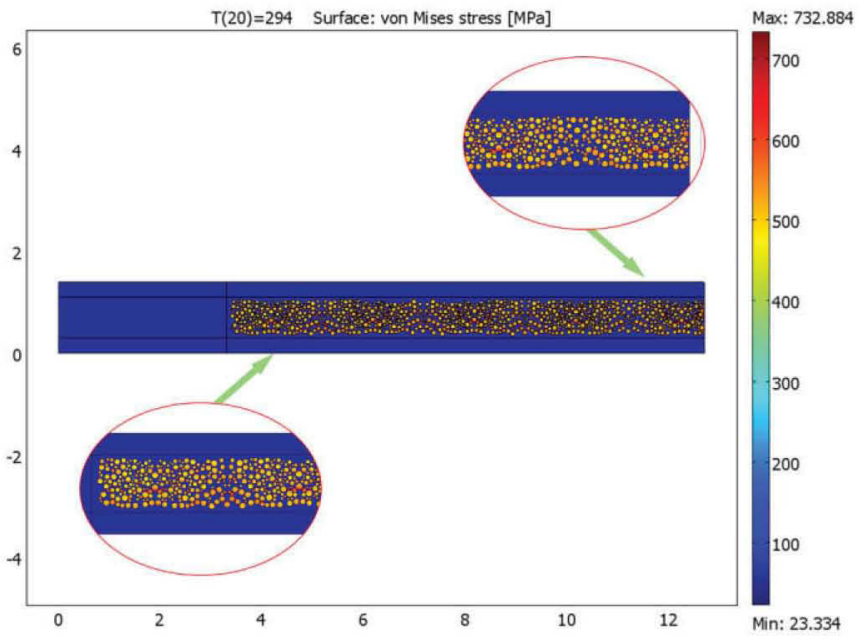

Figure 6 Equivalent stresses distribution in 2D

Mechanical response of the particles and the matrix with respect to temperature is shown in Fig. 7. Even though particles hold average $400 \mathrm{MPa}$ compressive residuals, maximum values were presented also. Maximum values were captured from the particles regardless of their location. It was noticed that residuals on the articles are higher where mesh densities increase due to the sharp corners between the particles. One might use even finer mesh to get more precise results for the sharp corners of the particles, if particles alone are concern. Matrix material (A16061-TO) follows the flow rule presented in material data previously and reaches to complete yielding. Consequently, $55 \mathrm{MPa}$ residuals on the matrix at the end of the Hot Rolling should be expected.

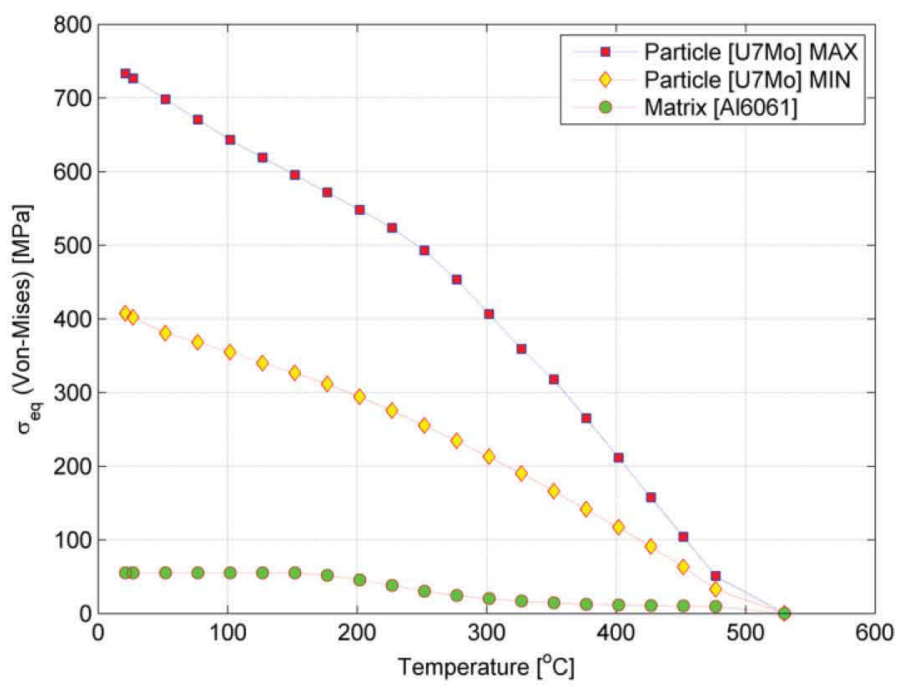

Figure 7 Stress history for the particles and the matrix

\section{BLISTER ANNEALING}

\subsection{FE Model}

Blister annealing is a common practice to ensure that no blisters develop on the surface, which would be an indication of poor bonding between the fuel meat and the cladding. During blister annealing, plates are exposed to $485^{\circ} \mathrm{C}(758 \mathrm{~K})$ for 60 minutes. Since residual stresses were identified via microstructural based simulation, solution was used for subsequent simulations. Obviously, whole plate could be modeled by using a repetitive microstructure in 3D. However, this would be computationally very expensive. Therefore, two distinct simulations were considered. First one considers the overall response of the plates in $3 \mathrm{D}$ and second one investigates the particle response in microstructural level.

Because of the symmetry, only one-half of the plate was modeled. Since eight-node hexahedral elements produce more accurate results, brick elements with mapped meshing were used for discretization. Fuel was represented by using 3 layers totaling 2250 quadratic elements, while cladding was represented by 9 layers contains 8280 quadratic elements. Elasto-thermo-perfectly-plastic material models were assigned to both cladding material and fuel compound to simulate thermo-plasticity. One node (lower left corner) of the model was constrained in three directions to prevent rigid body motion. On the mid boundary, symmetry condition was assigned to corresponding nodes. Half symmetric FE model along with partial cut is shown in Fig. 8.

Residual stresses were introduced to the solver as an initial condition. Namely normal and shear components in all 3 directions were included on fuel compound. Elasto-plastic parametric solver with reduced integration was employed. Since amount of time under temperature is small, thermal creep was assumed to be zero. Fuel compound is mixture of $40 \% \mathrm{U} 7 \mathrm{Mo}$ and $60 \% \mathrm{Al} 6061$. Material properties of the compound which was presented previously were assigned accordingly. $21{ }^{\circ} \mathrm{C}$ was assumed to be reference point for the blister annealing simulation. At this temperature, plate was assumed to be free of any defects. Since, blister annealing require the plates to be exposed to $485^{\circ} \mathrm{C}, 22$ sub-steps with $25^{\circ} \mathrm{C}$ increase in each step were used to reach annealing temperature.

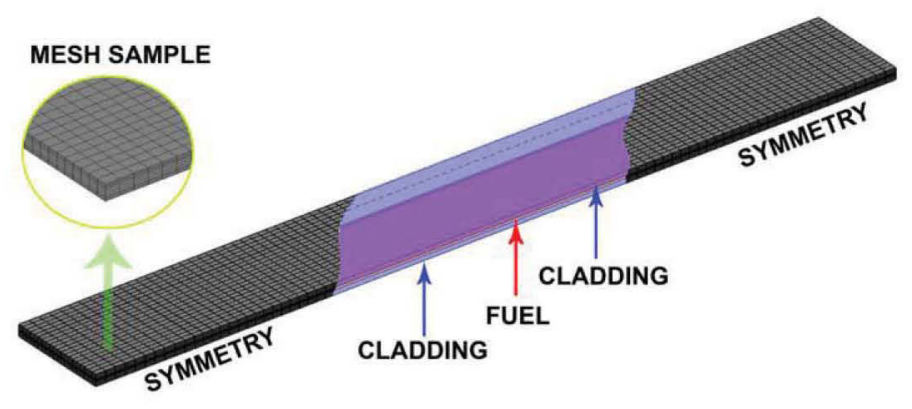

Figure 8 Half symmetric FE model 


\subsection{Results and Discussions}

Equivalent stress distribution and effective plastic strains are shown in Fig. 9 and Fig. 10 respectively.

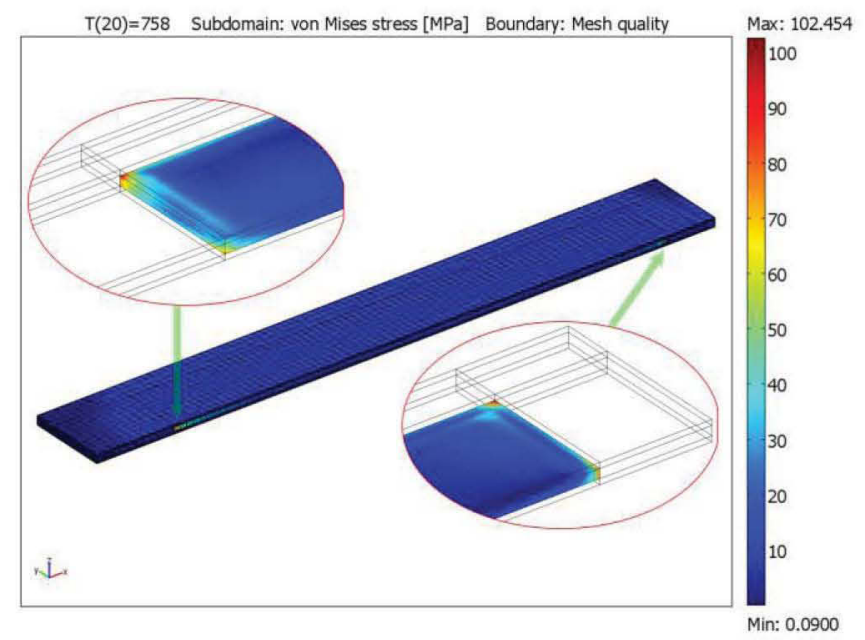

Figure 9 Equivalent stresses

It seems cladding material over the fuel region manifests further plastic deformations due annealing. However, blister acts as a stress relief on the plate body. Equivalent stress distribution on the fuel is more or less uniform; however, higher concentration was observed once closer to the fuel ends.

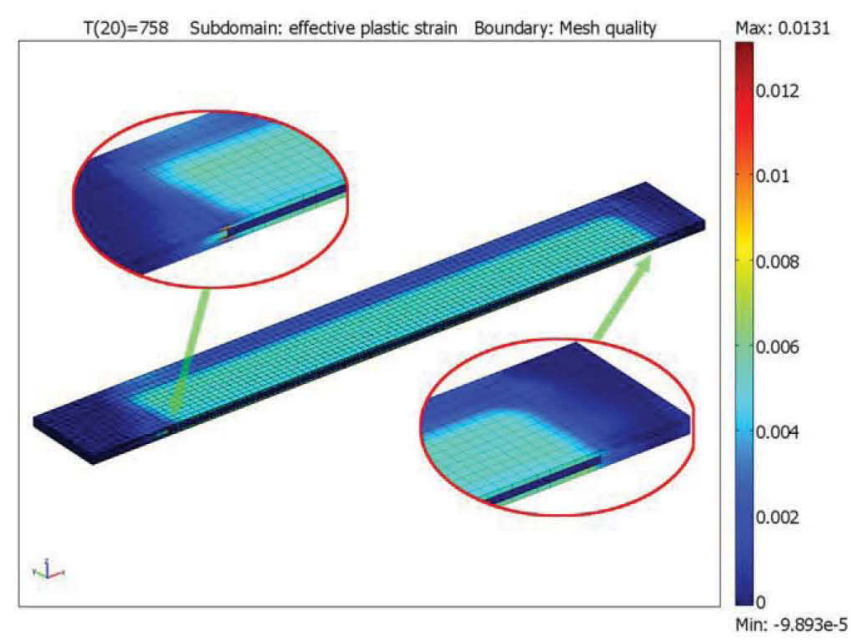

Figure 10 Effective plastic strains

To understand the response of the fuel region and fuel particles under blister annealing, microstructure based simulation was repeated. Same microstructural model presented before was modified to compute the response of the fuel region. Same boundary conditions and similar methodology were employed. Two stepped elasto-plastic parametric solver with reduced integration was used. Blister simulation was introduced as subsequent step for hot rolling simulation which was previously discussed. $21{ }^{\circ} \mathrm{C}$ was assumed to be reference point for the second step. Similarly, 22 sub-steps with $25^{\circ} \mathrm{C}$ increase in each step were created. Residual stresses from step 1 were introduced to the solver as an initial condition.

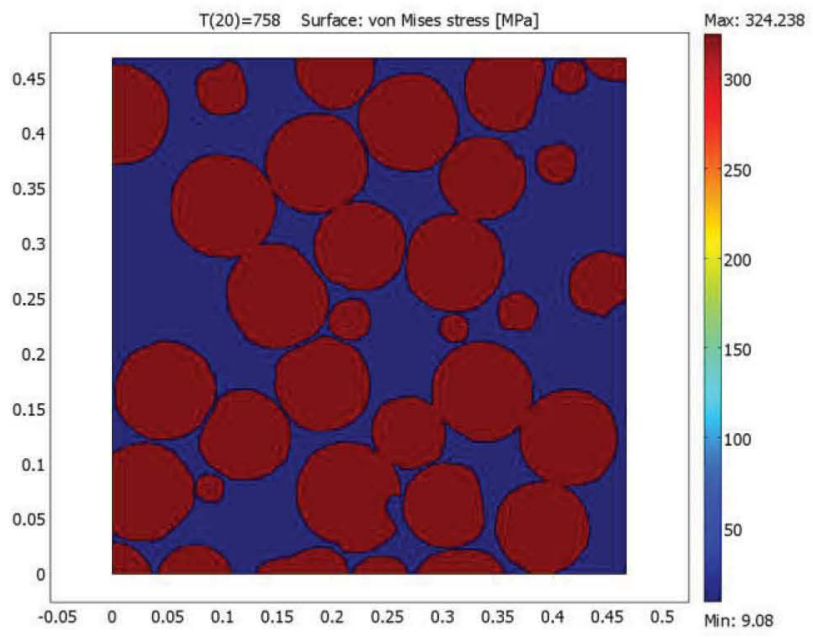

Figure 11 Particle response

Plastic strains are significantly lower on fuel particles. However high stress gradients were noted. Aluminum matrix has approximately $9 \mathrm{MPa}$ equivalent stresses while fuels register approximately $325 \mathrm{MPa}$. It seems blister acts as a stress relief on both matrix and particles.

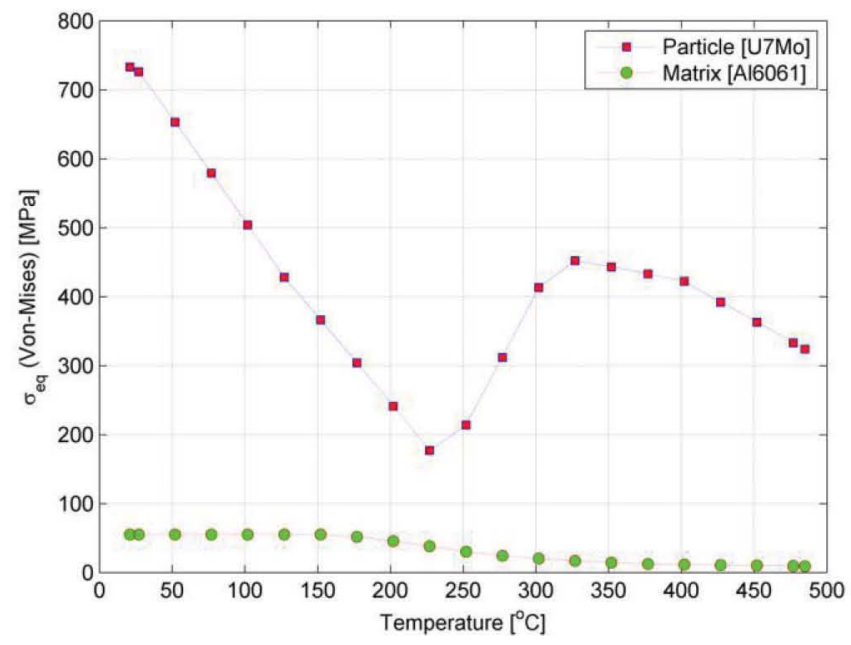

Figure 12 Blister Response of particles and matrix

Fig. 12 presents equivalent stress history calculated for the particles and matrix material. However, at approximately 225 ${ }^{\circ} \mathrm{C}$, normal stresses change direction from compression to tension. Equivalent stresses drop to $325 \mathrm{MPa}$ which is significantly lower than $730 \mathrm{MPa}$ as computed for the Hot Rolling. Assuming there are no significant microstructural changes that would hinder the mechanical properties, then, the plate should overcome the thermal stresses under extreme temperatures occurs during the annealing step. 


\section{IN-REACTOR RESPONSE}

\subsection{Multiphysics FE Model}

To provide an effective tool for benchmarking of structural response of the mini plates, it would be more realistic to use a simulation model as close as possible to the actual operating conditions. For this purpose, multi-step coupled multiphysics simulations were carried out. Once residuals and plastic strains due to fabrication process are identified via image based $\mathrm{FE}$ analysis as discussed previously, computed residuals were used as initial condition for subsequent multi-physics simulations. Since thermal response of the structure is driven by the amount of the heat removed by the primary coolant and, the heat removal rate is a function of the coolant velocity field and, coolant temperature increases while the coolant travels along the path in the mini plate capsule, fluid-structure interaction was coupled with fluid-thermal interaction. To achieve this, velocity and pressure fields of the coolant was computed via fluid-structural interaction with thermal dependency. Computed velocity and pressure fields were used to identify temperature fields on both coolant and on the fuel plate via coupled fluidthermal and thermal-structural interaction. Finally, computed temperature fields and residual distribution were supplied to the solver to obtain the mechanical response of the plate via coupled Fluid-Thermal-Structural interaction.

Because of the symmetry, only one-half of the plate (cut through from the mid-plane, i.e. fuel core) was modeled. Since eight-node hexahedral elements produce more accurate results, brick elements with mapped meshing were used for domain discretization. Fuel was represented by using 3 layers totaling 7500 quadratic elements, while cladding contains 16656 quadratic elements distributed to 6 layers. Coolant was represented with 10 layers totaling 40260 quadratic elements. Resulted finite element model is shown in Fig. 13.

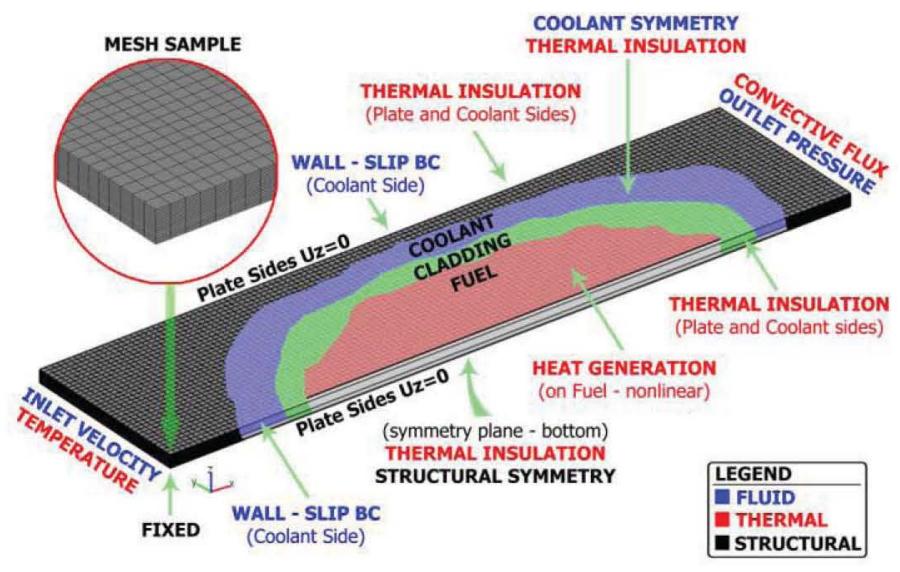

Figure 13 Coupled multi-physics FE setup

For fluid flow, temperature dependent viscosity and density were assigned to corresponding elements. Inlet velocity of 14 $[\mathrm{m} / \mathrm{sec}]$ and outlet boundary condition was assigned to corresponding nodes. Initial pressure of $2.56 \mathrm{MPa}$ was assigned to coolant section. Coolant sides were treated as wall boundaries and slip conditions were assigned accordingly. Similar with symmetry condition used for solid portion, due to the symmetry of the coolant, only half of the coolant was modeled and consequently, symmetry boundary condition was assigned to the nodes on the top of the coolant.

For thermal transport, temperature dependent thermal properties (conductivity, specific heat and density) were assigned to corresponding domains namely to fuel, cladding and coolant. Velocity fields from previous simulation were assigned to coolant. Inlet side was constrained with proposed inlet temperature $\left(52^{\circ} \mathrm{C}\right)$. Due to the small thickness of the plate, heat escape from the plate sides was assumed to be negligible and therefore, mini plate sides were treated as insulated boundaries. Symmetry/insulation boundary condition was assigned to the plate mid layer (i.e fuel core) as well as to symmetry plane for the coolant. Convective flux was assigned to the nodes located at outlet side. Heat source/sink condition was assigned to the nodes shared by solid and the coolant to handle the heat transfer between two. Due to non-uniform fission density, fuel matrix closer to ATR core has higher heat generation rate. For thermally accurate simulations, this nonlinearity should be considered. Heat generation rate was supplied to the solver via parametric formulation. Experimental data for fission density was used to compute the power profile shown in Fig. 14. Polynomial representation of the profile was multiplied with average heat generation rate of $10000 \mathrm{~W} / \mathrm{cm}^{3}$ to formulate the heat generation rate in space domain. Finally, relation shown in Eq. 16 was supplied to the solver to include this thermal non-linearity on the fuel compound.

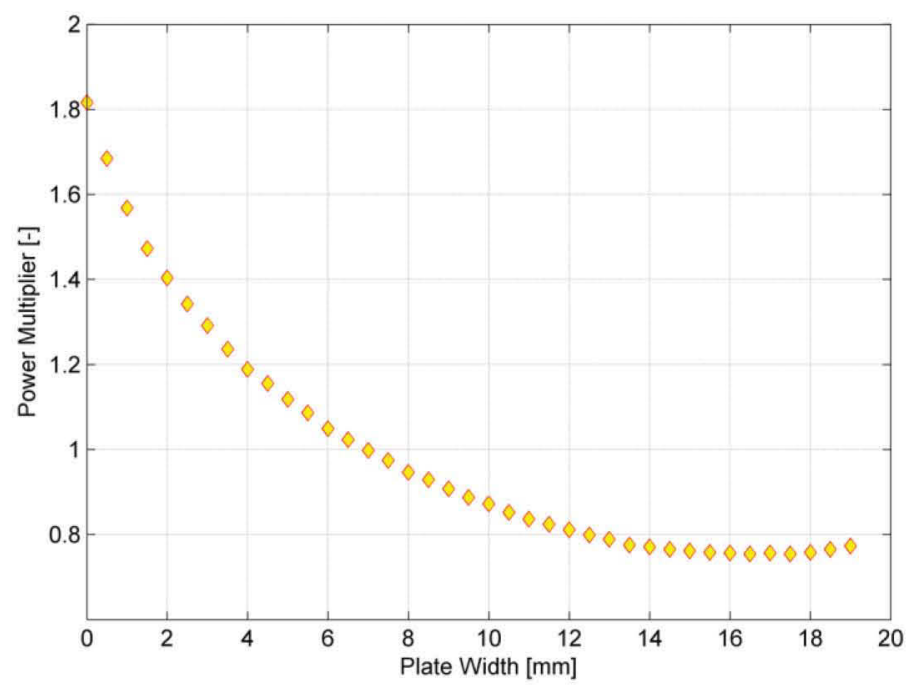

Figure 14 Power profile along the plate width

$$
\begin{aligned}
Q(x, t)= & P_{\alpha v}(t) *\left(0.00002783 * x^{4}-0.001278 * x^{3}+\right. \\
& \left.0.02321 * x^{2}-0.2231 * x+1.785\right)\left[\mathrm{W} / \mathrm{cm}^{3}\right]
\end{aligned}
$$


In Eq. 16, $\mathrm{Q}$ is the heat generation rate, $\mathrm{P}$ is average power $\left(10000 \mathrm{~W} / \mathrm{cm}^{3}\right.$ for this simulation) and $\mathrm{x}$ is the distance $[\mathrm{mm}]$ along the plate width.

For structural mechanics simulations, elasto-thermo-perfectlyplastic material models were assigned to both cladding and fuel materials to simulate thermo-plasticity. One node (lower left corner) of the model was constrained in three directions to prevent rigid body motion. Since fuel plate goes into a guided channel in fuel assembly, side nodes were constrained accordingly. On the mid boundary, symmetry condition was assigned to corresponding nodes. Residual stresses were introduced to the solver as initial condition. Namely normal and shear components in all 3 directions were added in to formulation. Thermal result of Fluid-Thermal interaction was assigned accordingly as loading to compute thermal displacements. Elasto-plastic parametric solver with reduced integration was employed. Since amount of time under temperature is small, thermal creep was assumed to have negligible effects. Fuel compound is mixture of $40 \%$ U7Mo and $60 \%$ Al6061 and material properties of the compound were assigned accordingly. The plate was assumed to be free of any defects at the room temperature (i.e. no premature cracks).

It should be noted that there exist possible convergence problems, once different physics with material non-linearity are coupled together and solved simultaneously. Making the coolant mesh unnecessarily dense would create equivalently dense structural mesh and therefore, structural mechanics might experience convergence problems, especially if solution goes in to plastic region. On the other hand, using too coarse mesh in solid section would lead to inaccurate temperature field and consequently wrong thermally driven stress fields. If the structural response is the ultimate goal, while still carefully considering other disciplines, several degrees of deviation in temperature field would not alter overall behavior of the plate dramatically. Optimizing the mesh density was left to reader's expertise and will not be discussed here. In addition, it is known that material properties degrade under irradiation and the plate experiences phenomenon such as particle swelling and irradiation induced creep. Since this article considers only initial response of the plates and data for these variables is not available yet, these phenomenon were not considered. However once degraded material properties are available, simulation results should be updated for full transient behavior.

\subsection{Thermal Response}

Even though temperature of the ATR's primary coolant does not appear in structural calculations, it affects the thermal solution of the solid domain due to its interaction with it. Once fluid motion was computed via Fluid-Structural interaction, velocity field were used to thermal response of the coolant. Figure 15 shows computed temperature field of the coolant film layer. As expected, coolant has $52{ }^{\circ} \mathrm{C}$ on the inlet side. Temperature gradients due to non-linear heat generation rate were noted. In addition, coolant experiences temperature increase while it travels through the channel. These thermal gradients closer to the outlet side are more noticeable. Highest temperature for film layer of the coolant was computed as $92.8^{\circ} \mathrm{C}$ as shown in the Fig. 15.

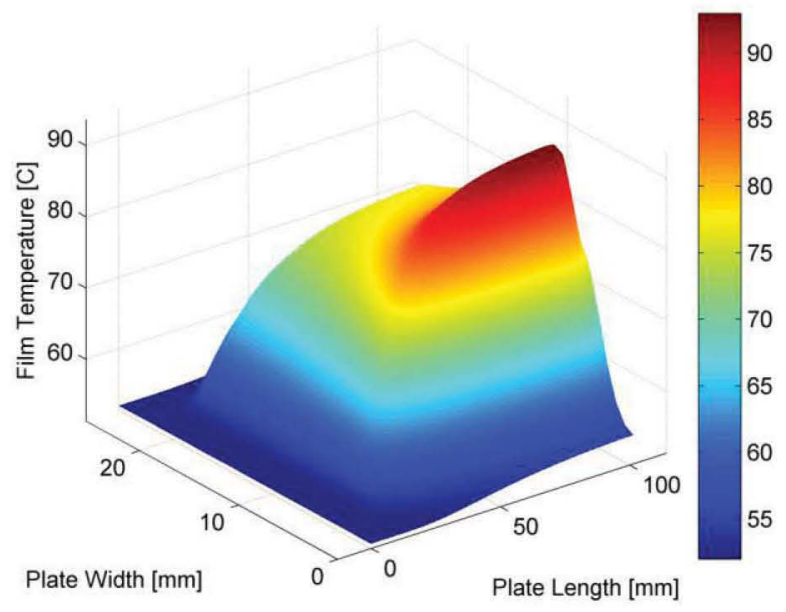

Figure 15 Temperature field of the primary coolant film

While cladding surface exhibits approximately $93^{\circ} \mathrm{C}$, maximum temperature between the cladding material and the fuel compound is approximately $102{ }^{\circ} \mathrm{C}$ as shown in Fig. 16. Not surprisingly, highest temperature was recorded closer to the ATR core on the outlet side of the primary coolant.

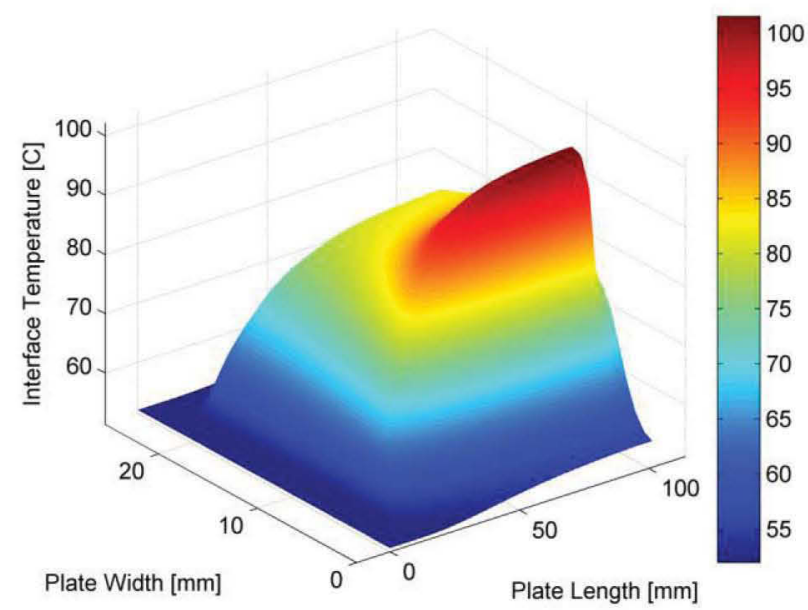

Figure 16 Temperature between cladding and fuel matrix

The temperature field for the fuel core (i.e. plate mid plane) is presented Fig. 17. Highest temperature computed for the fuel compound is approximately $108{ }^{\circ} \mathrm{C}$ on the outlet side of the coolant. Thermal gradients are more noticeable due to the non uniform heat generation rate as presented in Fig.14 and formulated in Eq. 16. Even though inlet side is considerably colder, plate experiences temperature increase closer to the 
outlet side due to the temperature increase of the ATR's primary coolant.

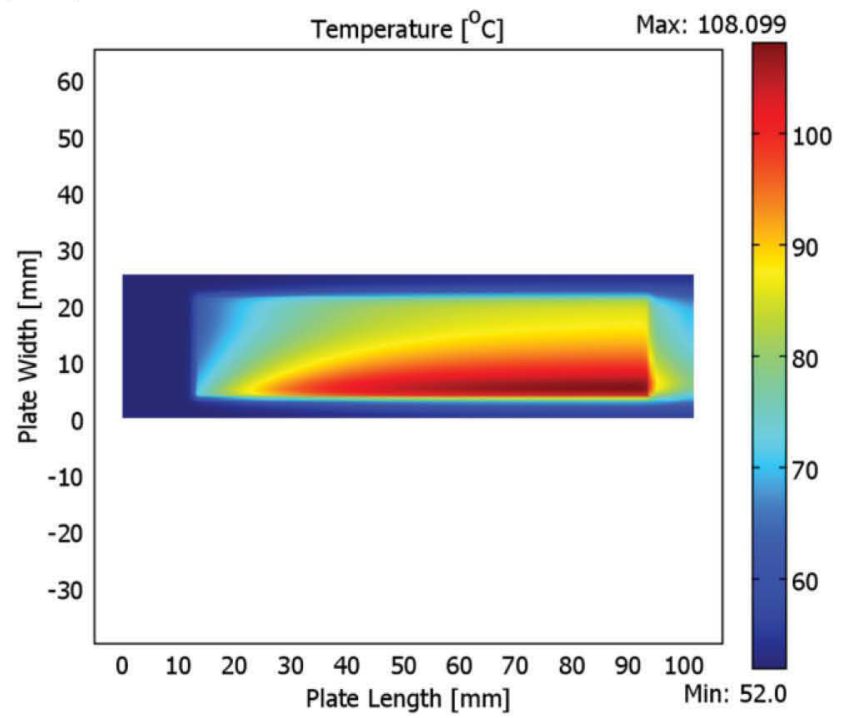

Figure 17 Temperature field at the fuel core (plate mid-plane)

\subsection{Structural Response}

The final step of the multiphysics simulations is to couple previously computed results. Residual stresses which were computed via parametric structural-thermal interaction (presented in Section 5.2), and temperature fields which were computed via coupled fluid-structural and thermal-fluid interaction (presented in Section 7.2) were used to simulate the structural response of the plate via thermal-structural interaction. Computed temperature values were assigned to corresponding nodes as thermal loads and residuals due to fabrication process were assigned accordingly as initial loading.

Figure 18 shows displacement field of the dispersion mini plate. Maximum total displacement was computed as 0.109 $\mathrm{mm}$, while directional displacements were $0.108 \mathrm{~mm}, 0.037$ $\mathrm{mm}$ and $0.0012 \mathrm{~mm}$ on $\mathrm{x}, \mathrm{y}$ and $\mathrm{z}$ respectively.

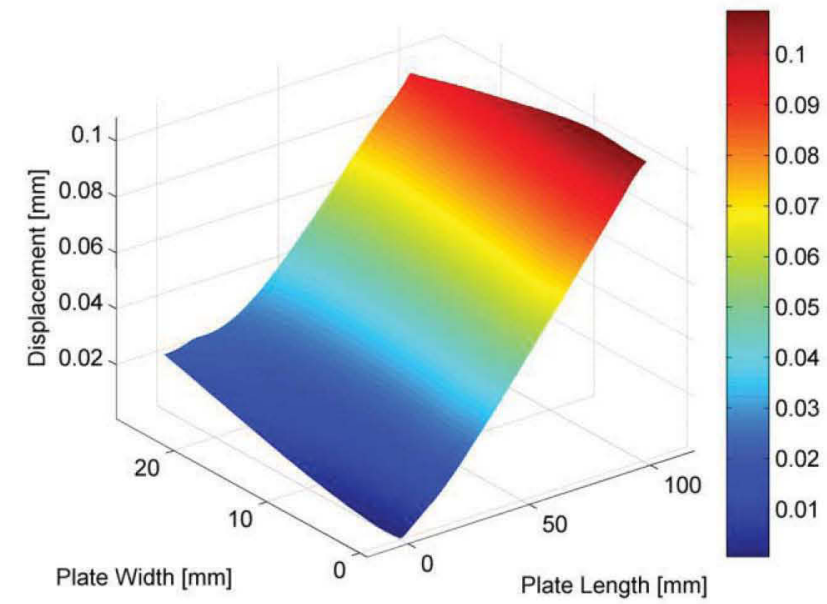

Figure 18 Total displacements on the plate
Corresponding strains to the directional displacements were computed as $0.0015,0.0021$ and 0.0020 on $\mathrm{x}, \mathrm{y}$, and $\mathrm{z}$ directions respectively.

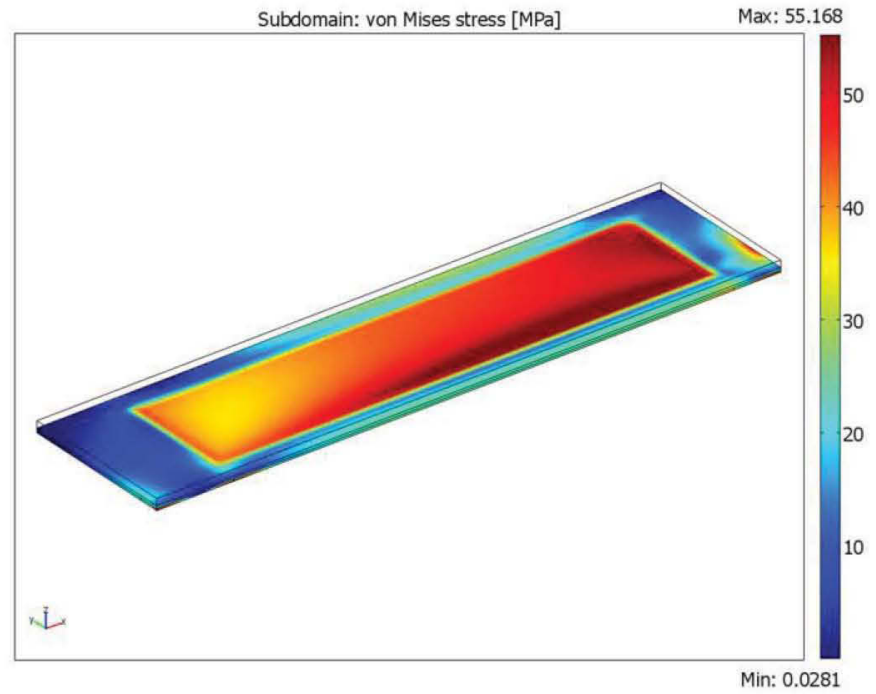

Figure 19 Equivalent stresses on the cladding

Equivalent stresses on the cladding material (Al6061-TO) are shown in Fig. 19. Cladding over the fuel region holds approximately $55 \mathrm{MPa}$ due to the fabrication induced residuals. No further plastic strains were noted in addition to plastic strains developed during the fabrication.

Figure 20 shows equivalent stress distribution on the fuel matrix (40\%U7Mo + 60\%AL6061). While fuel compound holds approximately $50 \mathrm{MPa}$, equivalent stresses increase to approximately $145 \mathrm{MPa}$ at regions close to the interface. Assuming there are no preexisted defects, fuel compound should not experience any problems due to the thermally driven stress gradients, if Von-Mises failure criteria is used.

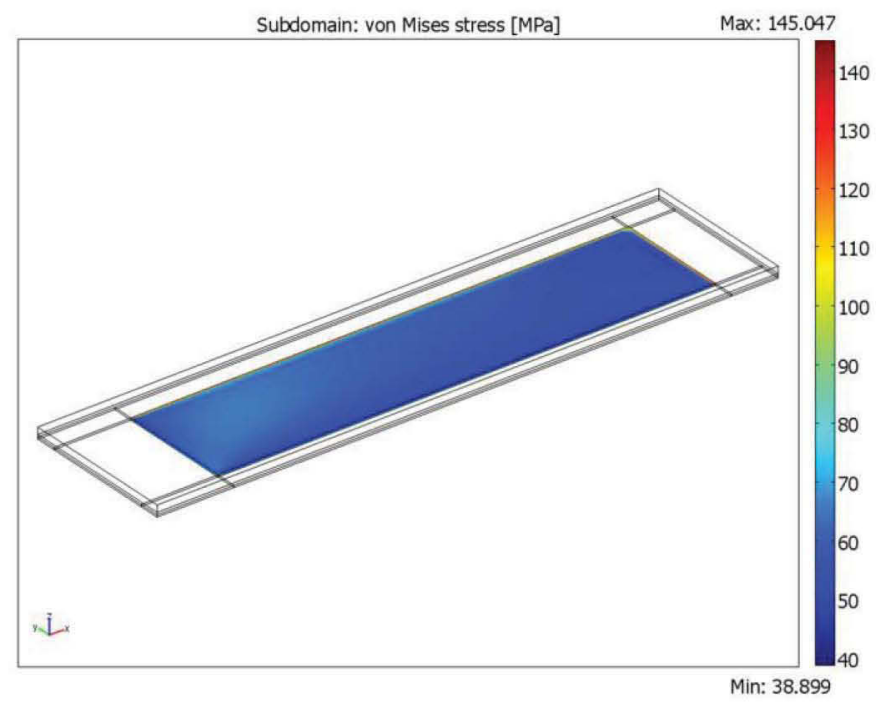

Figure 20 Equivalent stresses on the fuel compound 
Figure 21 shows equivalent stresses distribution on the fuel cladding interface to further investigate the gradients. Fuel compound-cladding interface registers approximately $65 \mathrm{MPa}$.

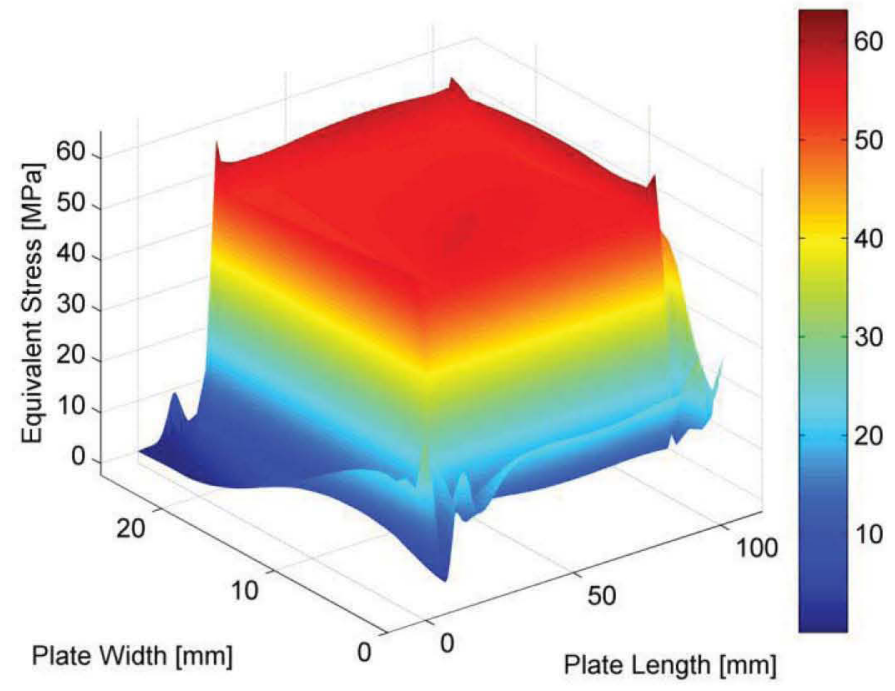

Figure 21 Equivalent stresses on the fuel cladding interface

Figure 22 shows equivalent stresses distribution on the cladding surface. Highest stresses were computed as $55 \mathrm{MPa}$ and found to be closer to the outlet side of the reactor core.

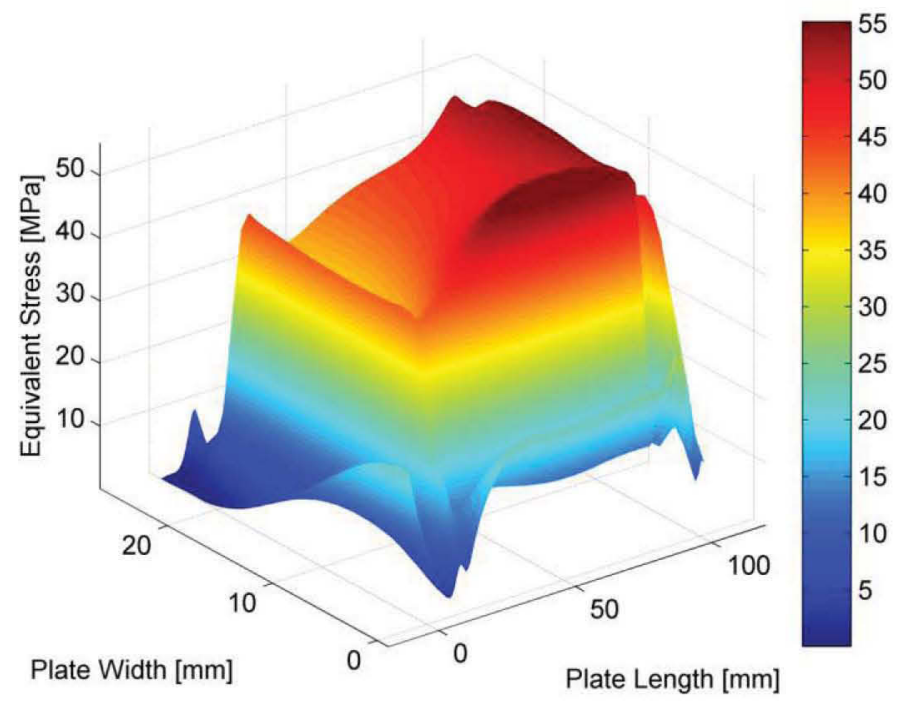

Figure 22 Equivalent stresses on the cladding surface

Obviously, whole plate can be modeled by using microstructure. However, this would be computationally very expensive. If particle response alone is a concern, similar methodology can be employed to simulate the particle responses in micro-scale. However, purpose of this article was overall response of the plate; therefore, this simulation will not be discussed here.

\section{CONCLUSIONS}

Thermo-mechanical response of the dispersion fuel mini-plates under in-reactor conditions was investigated. The analysis demonstrated that residual stresses still govern the mechanical response of the plate. Compared to proposed monolithic fuel, dispersion plates showed significant compliance. Unless there is a micro failure (i.e. particle-Al matrix separation), in overall, plate demonstrated no structural weakness under in reactor conditions. Since this article considered initial response of the plate, particle swelling, creep and material degradation were not included. For full transient behavior, these variables should be included in micro scale when the material data becomes available.

\section{ACKNOWLEDGMENTS}

This manuscript has been authored under Contract Number DEAC07-05ID14517 with the U.S. Department of Energy. The U.S. Government retains and the publisher, by accepting the article for publication, acknowledges that the U.S. Government retains a nonexclusive, paid-up, irrevocable, world-wide license to publish or reproduce the published form of this manuscript, or allow others to do so, for U.S. Government purposes.

\section{NOMENCLATURE}

$\mathrm{C}_{\mathrm{p}} \quad$ Specific heat capacity

$D_{i j k l} \quad$ Elasticity matrix

$\mathrm{D}_{\mathrm{H}} \quad$ Hydraulic diameter

E Modulus of elasticity

$F \quad$ Volume force field

$G \quad$ Shear modulus

$h \quad$ Heat transfer coefficient

$k \quad$ Thermal conductivity

$\mathrm{Nu} \quad$ Nusselt number

Pr Prandtl number

$p \quad$ Pressure

$Q \quad$ Heat source

Re Reynolds number

$T \quad$ Temperature

$\alpha_{k l} \quad$ Tensor for coefficient of thermal expansion

$\varepsilon_{i j} \quad$ Strain tensor

$\eta \quad$ Dynamic viscosity

$\sigma_{i j} \quad$ Stress tensor

$\rho$ Density

$u_{i} \quad$ Displacement

$v \quad$ Poisson's ratio 


\section{US DEPARTMENT OF ENERGY DISCLAIMER}

This information was prepared as an account of work sponsored by an agency of the U.S. Government. Neither the U.S. Government nor any agency thereof, nor any of their employees, makes any warranty, express or implied, or assumes any legal liability or responsibility for the accuracy, completeness, or usefulness of any information, apparatus, product, or process disclosed, or represents that its use would not infringe privately owned rights. References herein to any specific commercial product, process, or service by trade name, trademark, manufacturer, or otherwise, does not necessarily constitute or imply its endorsement, recommendation, or favoring by the U.S. Government or any agency thereof. The views and opinions of authors expressed herein do not necessarily state or reflect those of the U.S. Government or any agency thereof.

\section{REFERENCES}

[1] Snelgrove J.L., Hofman G.L., Meyer M.K., Trybus C.L., Wienceck T.C., 1997. "Development of Very-High-Density Low Enriched Uranium Fuels", Journal of Nuclear Engineering and Design, Vol.178, pp. 119-126.

[2] Lee D.B., Kim K.H., Kim C.K., 1997. "Thermal Compatibility Studies of Unirradiated U-Mo Alloys Dispersed in Aluminum," Journal of Nuclear Materials, Vol.250, pp.79-82.

[3] Park J.M., Kim K.H., Kim C.K., Meyer M.K., Hofman G.L., Strain R.V., 2001. "The Irradiation Behavior of Atomized U-Mo Alloy Fuels at High Temperature", Journal of Metals and Materials International, Vol.7, No.2, pp. 151-15.

[4] Meyer M.K., Hofman G.L., Hayes S.L., Clark C.R., Wienceck T.C., Snelgrove J.L., Strain R.V., Kim K.H., 2002. "Low Temperature Irradiation Behavior of U-Mo Alloy Dispersion Fuel", Journal of Nuclear Materials, Vol.304, pp. 221-236.

[5] Wang Q., Yan X., Ding S., Huo Y., 2010. "Research on the Interfacial Behaviors of Plate-Type Dispersion Nuclear Fuel Elements", Journal of Nuclear Materials, Vol.399, pp.41-54.

[6] Ryu H. J., Han Y. S., Park J. M., Park S. D., and Kim C. K., 2003. "Reaction Layer Growth and Reaction Heat of U-Mo/Al Dispersion Fuels using Centrifugally Atomized Powders" Journal of Nuclear Materials, Volume 321, pp. 210-220.

[7] Leenaers A., Berghe S. V., Koonen E., Jarousse C., Huet F., Trotabas M., Boyard M., Guillot S., Sannen L., Verwerft M., 2004. "Post Irradiation Examination of U7Mo Atomized Dispersion Fuel" Journal of Nuclear Materials, Vol.335, pp. 39-47.

[8] Ryu H. J., Park J. M., Kim C. K., Kim Y. S., and Hofiman G. L., 2006. "Diffusion Reaction Behaviors of U-Mo/Al Dispersion Fuel", Journal of Phase Equilibria and Diffusion, Vol.27, No.6, pp. 651-658.

[9] Berghe S. V. D., Renterghem W. V., Leenaers A., 2008. "Transmission Electron Microscopy Investigation of Irradiated U7Mo Dispersion Fuel", Journal of Nuclear Materials, Vol.375, pp. 340-346.
[10] Kim K.H., Lee D.B., Kim C.K., Hofman G.L., Paik K.W., 1997. "Characterization of U-2 wt \% Mo and U-10 wt \% Mo Alloy Powders Prepared by Centrifugal Atomization," Journal of Nuclear Materials, Vol.245, pp. 179-184

[11] Keiser D. D., Robinson A.B., Jue J.F., Medvedev P., Wachs D. M., Finlay M. R., 2009. "Microstructural Development in Irradiated U7Mo/6061 Al Alloy Matrix Dispersion Fuel", Journal of Nuclear Materials, Vol.393, pp.311-320.

[12] Lewis A.C., Geltmacher A.B., 2006. "Image-Based Modeling Of The Response of Experimental 3D Microstructures to Mechanical Loading", Scripta Materialia, Vol.55, No.1, pp.81-85.

[13] Chawla N., Sidhu R.S., Ganesh V.V., 2006. "3D Visualization And Microstructure-Based Modeling of Deformation in ParticleReinforced Composites", Acta Materialia, Vol.54, pp.154I-1548.

[14] Langer S.A., Fuller E.R., Carter W.C., 2001. "An Image Based Finite-Element Analysis of Material Microstructures" Joumal of Computing in Science and Engineering, Vol.3, No.3, pp.15-23.

[15] Ali J., Farooqi J.K., Buckthorpe D., Cheyne A., Mummery P., 2009. "Comparative study of predictive FE methods for mechanical properties of nuclear composites", Journal of Nuclear Materials, Vol.383, No.3, pp.247-253.

[16] Hsueh C.H., Becher P.F., Sun E.Y., 2001. "Analyses of thermal expansion behavior of inter-granular two-phase composites" Journal of Material Science., Vol.36, No.1, pp. 255-261.

[17] Polkinghorne S.T., Lacy J.M., 1991. "Thermophysical And Mechanical Properties Of ATR Core Materials". EG\&G Idaho Inc., Internal Technical Report, PG-T-91-031.

[18] Rest J., Kim Y. S., Hofman G. L., Meyer M. K., Hayes S. L., 2006 "U-Mo Fuels Handbook v.1.0", Argonne National Laboratory Internal Report.

[19] Totev T., Hofman G., Looby M.,2009. "AA-MATPROHANDBOOK, Aluminum Material Properties for Research Reactor", Argonne National Laboratory Internal Report.

[20] Lee S.H., 2003. "Effect of Heat Treatment on Thermal Conductivity of U-Mo/Al Alloy Dispersion Fuel", International Journal of Thermophysics, Vol.24, No.5, pp.1355-1371.

[21] Lee S.H., 2007. "Thermophysical Properties of U-Mo/Al Alloy Dispersion Fuel Meats", International Joumal of Thermophysics, Vol.28, No.5, pp. 1578-1594.

[22] Zhang Z., Zhang H.W., 2007. "Material Behaviors and Mechanical Features in Friction Stir Welding Process", International Journal of Advanced Manufacturing Technology, Vol.35, pp.86-100. 